\title{
Virchow 2.0 and physician advocacy
}

\section{From call to effective action}

\author{
Lawrence C. Loh MD MPH FCFP FRCPC Nikhil Rajaram MD CCFP MPH FRCPC
}

nterest in advocacy by physicians has reached unprecedented levels, with traditional and Internetbased media being employed to mobilize an array of agendas. ${ }^{1,2}$ Still other physicians have entered politics, ${ }^{3}$ and key national bodies have identified advocacy as an important physician activity, including the Canadian Medical Association, ${ }^{4}$ the College of Family Physicians of Canada, ${ }^{5}$ and the Royal College of Physicians and Surgeons of Canada (RCPSC), ${ }^{6}$ which has led medical educators to call for advocacy training as a fundamental component of learning.

Many physician advocates often reference the words of Rudolf Virchow as a rallying cry, recalling that "Medicine is a social science, and politics is nothing else but medicine on a large scale."7 However, on careful examination of this part of Virchow's statement, it seems to leave open what physician involvement in advocacy might look like with respect to content, approach, and outcomes.

We recognize that a range of activities might be considered physician advocacy. Table 1 outlines key competencies under the RCPSC CanMEDS role of health advocate that demonstrate this range, from advocacy for individual patients to action that fosters system-level change. ${ }^{6}$ While advocacy for individual patients remains a cornerstone of practice that is relatively simple to measure, our focus is on increasingly prominent physician efforts to drive large-scale system changes. Through discussing specific examples of such engagements, we aim to propose practices and principles to make physician advocacy more precise and effective.

\section{Effectiveness in physician advocacy}

In exploring the effectiveness of physician advocacy efforts, we propose to examine 2 questions:

- What activities are considered "high-level" physician advocacy?

- To what extent do these activities need to objectively advance health outcomes?

The RCPSC's high-level definition leaves open the possibility that "effectiveness" in physician advocacy might range from a physician simply having spoken up for a cause to objective success in driving large-scale societal changes. If we base effectiveness simply on the act of engaging, then instances in which physicians simply take a stand without broader objective change might be considered effective, as seen in recent efforts of US-based physicians advocating for stricter gun control measures. ${ }^{8}$ However, if we accept that many physicians will often engage in advocacy as a moral imperative, we might instead define effectiveness as being measured by the observed outcomes achieved by the advocacy efforts, rather than simply amplifying a specific position.

In focusing on outcomes, the next question asks to what extent physician advocacy should objectively and ultimately advance health in order to be considered effective. One example is Canada's long-standing debate around 2-tiered health care, with physicians on both sides of the issue arguing for and against greater private sector involvement in health care. Evidence from other countries largely favours those who defend Medicare, although proponents of for-profit medicine are persuasive with some quarters in justifying how their position will improve health care outcomes. ${ }^{9}$

\section{Table 1. Royal College of Physicians and Surgeons of Canada CanMEDS framework key competencies for the role of} health advocate

\begin{tabular}{|c|c|}
\hline KEY COMPETENCIES & ENABLING COMPETENCIES \\
\hline Physicians are able to ... & \\
\hline $\begin{array}{l}\text { 1. Respond to an individual patient's } \\
\text { health needs by advocating with } \\
\text { the patient within and beyond the } \\
\text { clinical environment }\end{array}$ & $\begin{array}{l}\text { 1.1 Work with patients to address determinants of health that affect them and their access } \\
\text { to needed health services or resources } \\
\text { 1.2 Work with patients and their families to increase opportunities to adopt healthy } \\
\text { behaviour } \\
\text { 1.3 Incorporate disease prevention, health promotion, and health surveillance into } \\
\text { interactions with individual patients }\end{array}$ \\
\hline $\begin{array}{l}\text { 2. Respond to the needs of the } \\
\text { communities or populations they } \\
\text { serve by advocating with them for } \\
\text { system-level change in a socially } \\
\text { accountable manner }\end{array}$ & $\begin{array}{l}\text { 2.1 Work with a community or population to identify the determinants of health that affect } \\
\text { them } \\
\text { 2.2 Improve clinical practice by applying a process of continuous quality improvement to } \\
\text { disease prevention, health promotion, and health surveillance activities } \\
\text { 2.3 Contribute to a process to improve health in the community or population they serve }\end{array}$ \\
\hline
\end{tabular}


Perplexingly, the Royal College definition might suggest that both sides are engaged in effective advocacy through supporting a call for change and speaking on behalf of others in using their expert credentials to advance their cause. We propose, however, that physician advocacy cannot truly be effective if it is not done with the aim of objectively advancing health. Evidence suggests that Medicare-supporting physician advocates more closely meet the definition of effectiveness.

All things considered, these points suggest that measuring effective physician advocacy must be predicated on how well such efforts ultimately drive improved health outcomes, the latter being measured indirectly through metrics such as implementation of optimal health policy or programs.

\section{Providing attribution in physician advocacy}

Accepting that effective advocacy must be linked to improved health outcomes through measured changes in context, the next step is to clearly define scope and attribution around physician involvement.

Here, the Royal College's definition again presents challenges owing to its breadth. As an example, one of the described goals is for physicians to promote health equity, prevent disease, and protect and promote health. ${ }^{6}$ This, in fact, is the mandate of the entire governmental public health system, which leaves one wondering how best a single physician advocate might bring his or her efforts to supporting goals already being worked on by whole public health agencies and community organizations.

The definition adds further confusion by clarifying that "advocacy often requires engaging other [stakeholders]" but stating that physicians might "support or lead the mobilization of resources ... on small or large scales [emphasis added],"6 which risks role confusion. The reality is that, in many instances, a physician's contribution is one among those of many stakeholders acting within a complex interplay between many factors such as timing, context, governmental goals, and the work of other interested parties.

If we return to the 2-tiered health care debate in Canada, the importance of scope and attribution in effectiveness is well illustrated in the published biography of a recent award recipient from the Canadian Medical Association, which states that the physician's singular influence "probably prevented two-tier models of care from developing in several provinces" through the mid-2000s. ${ }^{10}$

Such a statement presents several challenges. It ignores contemporaneous context-the 2004 federal 10-Year Plan to Strengthen Healthcare ${ }^{11}$ provided billions of dollars to increase access to priority medical services while obscuring the contributions of myriad stakeholders such as Canadian nurses, the labour movement, and nonphysician non-governmental organizations. ${ }^{12}$
For other physician advocates, the statement also paints somewhat unrealistic expectations for what their own efforts might achieve.

Unlike advocating for individual patients, effectiveness in broad-scale physician advocacy requires recognition of how one's role intersects with that of other stakeholders as outlined in the "partnership" aspect of the Royal College definition. Physician advocates are often effective because they employ their privilege to speak on behalf of many invisible hands and voices on the ground. Effective advocacy thus requires careful introspection about the physician's role while ensuring credit for successes in changing contexts is fairly given to all partners involved.

\section{On stretching the limits of physician expertise}

Having discussed scope and attribution, we turn then to expertise. In considering effectiveness, to what extent do physician advocates have to possess knowledge and authority on the topic at hand?

Physicians are experts in many topics that they might advocate for, often related to health care and the biomedical sciences, but many topics lie outside of physicians' training and experience, which we argue limits the credibility and effectiveness of their efforts. One recalls the old adage about the "triad" that physicians engage in out of medical school without formal training: teaching, research, and running a business. This situation, however, extends to many other topics and activities outside many physicians' traditional knowledge base.

An example: In fall 2017, proposed changes to Canadian-controlled private corporation tax regulations brought out 2 opposing physician advocacy camps, for and against the changes. ${ }^{13,14}$ This debate quickly devolved into the typical realm of tax economists and financiers, and while some physicians might share that expertise, outsiders likely saw the 2 camps as self-serving and overreaching, respectively. Simply stated, while all physicians are taxpayers, not all physicians are necessarily experts in taxation.

Another example concerns climate change, where physicians should definitely speak on the potential health effects to justify mitigation. However, absent additional training, physicians speaking to the evidence and details of specific mitigation measures (eg, carboncapture technologies) could be trespassing on areas otherwise better addressed by experts such as engineers and climate change professionals.

Effective advocacy requires physician advocates to determine if their expertise on a topic allows them to speak as an expert versus as a member of the general public. This is in keeping with scope-of-practice boundaries that are fundamental to many other aspects of physician practice; you would not typically find a general surgeon doing psychotherapy or an emergency 
physician practising public health leadership and epidemiology without undergoing retraining and assessment.

Hence, a final rule of thumb for effective physician advocacy might be best summed up in a question: Can I speak expertly on this topic? This would allow physicians to determine if they might be best placed to lead, support a coalition of advocates through bringing a medical perspective, or, in certain instances, hold back an uninformed opinion but provide general support to the cause.

\section{Bringing it all together}

As it turns out, the commonly used rallying cry based on Virchow's statement often misses the second half of his thoughts, which state: "Medicine as a social science, as the science of human beings, has the obligation to point out problems and to attempt their theoretical solution; the politician, the practical anthropologist, must find the means for their actual solution." ${ }^{17}$ Viewed in this fuller context, we interpret this to mean that Virchow did not intend for physicians to become the sole advocates for all the ills of the world.

In naming politicians, the quote also recognizes that the ultimate exercise in decisions within democracies exists in elected office and the will of the people. It also makes clear that physicians are not meant to lead and engage in every issue of interest but, specifically, are meant to identify and hypothesize on problems salient to the "science of human beings."

One can hence argue that Virchow's words describe to some extent the scope of effective physician advocacy as advanced in this paper: a focus on positive health outcomes, with physicians as health experts who inform decisions and solutions, leading where their expertise permits and partnering with key stakeholders where the considerations extend beyond medicine alone.

Dr Loh is Medical Officer of Health for Peel Public Health in Mississauga, Ont, and Adjunct Professor in the Dalla Lana School of Public Health in Toronto, Ont. Dr Rajaram is Lecturer in the Division of Occupational Medicine in the Department of Medicine at the University of Toronto.
Competing interests

None declared

The opinions expressed in commentaries are those of the authors. Publication does not imply endorsement by the College of Family Physicians of Canada.

References

1. Buchman S, Woollard R, Meili R, Goel R. Practising social accountability. From theory to action. Can Fam Physician 2016;62:15-8 (Eng), 24-7 (Fr).

2. Bhate TD, Loh LC. Building a generation of physician advocates: the case for including mandatory training in advocacy in Canadian medical school curricula. Acad Med 2015;90(12):1602-6.

3. Collier R. Profile: Dr. Jane Philpott. CMAJ 2016;188(2):100-2. Epub 2016 Jan 11.

4. Canadian Medical Association. Health advocacy [website]. Ottawa, ON: Canadian Medical Association. Available from: https://www.cma.ca/health-advocacy. Accessed 2019 Sep 8.

5. College of Family Physicians of Canada. Four principles of family medicine. Mississauga, ON: College of Family Physicians of Canada. Available from: https:// www.cfpc.ca/Principles/. Accessed 2019 Sep 8.

6. Sherbino J, Bonnycastle D, Côté B, Flynn L, Hunter A, Ince-Cushman D, et al. Health advocate. In: Frank JR, Snell L, Sherbino J, editors. CanMEDS 2015 physician competency framework. Ottawa, ON: Royal College of Physicians and Surgeons of Canada; 2015.

7. Virchow RC. Collected essays on public health and epidemiology. Vol 1. Rather LJ, editor. Boston, MA: Science History Publications; 1985.

8. Pane LM. It's a Twitter war: doctors clash with NRA over gun deaths. Associated Press 2018 Nov 21. Available from: https://www.apnews.com/ef9238dd2b75447d8fc 1c0b3144d508f. Accessed 2019 Sep 8.

9. Mertl S. BC refutes Charter challenge of Medicare. CMAJ 2016;188(15):E369-70. Epub 2016 Sep 19.

10. Canadian Medical Association. F.N.G. Starr Award-2019 recipient. Ottawa, ON: Canadian Medical Association; 2019. Available from: https://www.cma.ca/f-n-gstarr-award-2019-recipient. Accessed 2019 Sep 8.

11. A 10-year plan to strengthen health care. Ottawa, ON: Government of Canada; 2004 Available from: https://www.canada.ca/en/health-canada/services/health-caresystem/health-care-system-delivery/federal-provincial-territorial-collaboration/ first-ministers-meeting-year-plan-2004/10-year-plan-strengthen-healthcare.html. Accessed 2020 Oct 30.

12. Canadian Museum of History. Making Medicare: the history of health care in Canada, 1914-2007. Gatineau, QC: Canadian Museum of History; 2010. Available from: https:// www.historymuseum.ca/cmc/exhibitions/hist/medicare/medic-8h21e.html. Accessed 2019 Sep 8.

13. Ontario Medical Association. Proposed federal tax changes. Toronto, ON: Ontario Medical Association; 2019

14. An open letter to Minister Morneau. From physicians and medical students with a shared perspective on the proposed tax changes [website]. Available from: https:// docsandtaxes.wordpress.com/. Accessed 2019 Sep 8.

This article has been peer reviewed. Can Fam Physician 2020;66:844-6. DOI: $10.46747 / \mathrm{cfp} .6612884$

Cet article se trouve aussi en français à la page $\mathbf{8 8 7}$. 